\title{
OS CORPOS DA LIDERANÇA: AS TRAMAS DA FICÇÃO DO DISPOSITIVO CULTURAL DO FITNESS
}

\author{
María InÉS LANDA*
}

\begin{abstract}
Toda sociedade produz seus outros, mas cada tipo de sociedade fabrica sua própria classe de estranhos, e os faz de um jeito inimitável.
\end{abstract}

(Zygmunt Bauman)

RESUMO: $\mathrm{O}$ artigo procura os principais vetores que constituem a corporização (embodiment) da liderança como um dos princípios axiológicos mais característicos do novo capitalismo. Para isso, analisam-se, como expoente ideal que condensa esse ethos, as dinâmicas de produção e transformação do corpo do fitness. Abrese uma série de narrativas que evidenciam os processos pelos quais a performance do fitness vira um conjunto de valores que caracterizam ao empresário de si mesmo como uma figura emblemática do novo capitalismo. Conclui-se que as práticas corporais do fitness, observadas nas diagramáticas sociolaborais pós-fordistas, outorgariam ao praticante um repertório de recursos sobre o corpo e a própria personalidade, que se adequam para navegar nas agitadas águas do mercado capitalista contemporâneo.

Palavras-chave: Capitalismo avançado. Liderança. Organizaçōes do fitness. Corpo do fitness.

Doutora em Teoria da Literatura e Literatura Comparada e pesquisadora do Consejo Nacional de Investigaciones Científicas y Técnicas (Conicet), Argentina. E-mail: landa.mi@gmail.com 
Os corpos da liderança: as tramas da ficção do dispositivo cultural do fitness

\title{
LEADERSHIP'S BODIES: THE FICTIONAL STRATAGEM OF FITNESS CULTURAL DEVICE
}

\begin{abstract}
This article tracks the main vectors that shape the embodiment of leadership as one of the most representative axiological principles of the new capitalism. In order to accomplish this objective, it analyzes the process of production and transformation of the fit body as the ideal that portraits this ethos. Also, it elucidates some of the specifics narratives that underlie the dynamics of fitness' performance, those that allow elaborating connections with the values that characterize the figure of the self entrepreneur. This paper concludes that the practice of fitness, in the context of new capitalism, would give the consumers of fitness products a set of subjective and corporeal resources that would fit in the vertiginous and unpredictable waters of contemporaneous labour market.
\end{abstract}

Key words: Advanced capitalism. Leadership. Fitness organizations. Fit body.

\section{Introdução}

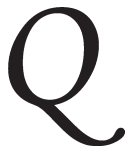

ualquer cidade do mundo, não importa em qual ponto do planeta ela se ache, apresenta uma constante, que hoje nos interessa problematizar: a presença imanente de imagens que prescrevem corpos plásticos, sorrisos em rostos imaculados e promessas de felicidade. As corporalidades de milhões de mulheres e homens (se é que com estas duas categorias saturam-se nossas possibilidades corporais) aparecem confrontadas, de modo contínuo, com iconografias e histórias ${ }^{1}$ que se interpelam na sua condição de recursos, encenando-os como coisas que devem ser vistas, desejadas, cultivadas e geridas. Para isso, põe-se à disposição dos sujeitos um interminável número de produtos e tecnologias orientadas a oferecer o corpo que eles desejam. Ser jovem, estar em forma e ter um corpo tonificado viraram ficçōes somáticas de nossos tempos. Não há escusas para ficar doente, ter sobrepeso ou envelhecer. É uma questão de vontade, de querer estar bem, e todos esses dispositivos estão ao nosso alcance (se pudermos pagá-los), para nos ajudar a conquistar nossos objetivos.

Por outro lado, Bolstanski e Chiapello (2002), nas suas análises sobre as atualizações do novo espírito do capitalismo, identificam como 
requisito para sobreviver em um mundo em rede que o sujeito se apresente como adaptável, flexível, abastecendo-se de um "estado" de disponibilidade indefinida para a geração das novas conexões. A adaptabilida$\mathrm{de}^{2}$ e a flexibilidade no capitalismo avançado são qualidades que não têm nada a ver com a docilidade. O "grande" da "cidade por projetos" é ativo e autônomo, é líder dele mesmo, líder nas suas relações de cima a baixo, líder nas suas redes (Bolstanski \& Chiapello, 2002, p. 167). A ética e a estética do "empresário de si mesmo" encarnam: saúde, pró-atividade, autonomia, polivalência, flexibilidade, firmeza, beleza, juventude e dinamismo (Du Gay, 1996; Landa, 1999). Todos os atributos corporais estão associados com o sujeito empresário, requerido nos diversos espaços laborais emergentes no contexto argentino e mundial.

Precisamente, é intenção do presente artigo achar os principais vetores que constituem a corporização (embodiment) da liderança, como um dos princípios axiológicos mais característicos do novo capitalismo. Para isso, tem-se escolhido como expoente ideal que condensa o ethos do empresário de si mesmo ao fitbody, principalmente às dinâmicas de sua produção e transformação.

\section{O corpo do fitness}

Um corpo, sua imagem, sua forma, sua função, seus movimentos, vestimentas e gestos nos levam imediatamente a um sujeito, o qual se acha numa ordem simbólica, própria de uma determinada constelação histórica (Torrás, 2007). Cada sociedade constrói específicas ficções narrativas que atribuem, a determinadas comunidades, a continuidade de um sujeito (Nouzeilles, 2000). Os corpos, em parte, são efeitos desses relatos maestros. ${ }^{3}$

Atendendo aos atuais deslocamentos das fronteiras que antigamente teriam regulamentado o comportamento das sociedades modernas ocidentais - separando a vida pública das cenas domésticas, privadas e íntimas -, vemos proliferar um conjunto de práticas corporais que estariam expressando novas convenções - outro pacto social em teares - e, simultaneamente, modelando novas formas, a partir das quais os sujeitos se ligam com o próprio corpo e com o corpo dos outros.

Neste sentido, o fitness, ${ }^{4}$ como locus onde circulam as ficções corporais dominantes do presente, representa, ao modo de produção atual, 
aquilo que a educação física simbolizou durante a época do fordismo industrial (Landa, 2009a). Uma das hipóteses sobre as quais se baseiam as reflexões que aqui apresentamos é que a ideologia do fitness constitui tanto um repertório para moldar e transformar o corpo, segundo uma axiologia específica, quanto um elo de um dispositivo técnico de (auto)governo e subjetivação, conforme o princípio instrumental de reprodução e acumulação do capitalismo avançado (Vázquez García, 2005).

O fit body, no interior desta conjuntura (con)textual, torna-se um resultado das máquinas narrativas das empresas do fitness. $\mathrm{Na}$ continuação, aprofundo as dinâmicas de produção do referido corpo, cuja construção supõe a confluência de específicos saberes, práticas e discursos ético-estéticos.

\section{O sujeito ideal do fitness: um empresário de si mesmo}

Segundo manifestei nos parágrafos anteriores, o corpo do fitness emerge como o modelo corporal que condensa a axiologia empresarial contemporânea. Aqui, abordarei os vetores fundamentais que o definem como um tipo ideal deste conjunto de práticas corporais. Para isso, tenho setorizado a análise em três eixos analíticos: o estético, o sanitárioterapêutico e o subjetivo.

A dimensão estética do fit body faz-se visível nas imagens dos corpos (feminino e masculino) exibidos nas diversas publicidades dos produtos do fitness; a dimensão sanitário-terapêutica aglutina os saberes que legitimam os processos de produção, transformação e manutenção do fit body: medicina desportiva, ciências do treinamento; fisiologia do exercício, entre outros. Finalmente, a dimensão subjetiva leva-nos a uma ideia de sujeito e de mundo que é imanente às primeiras duas dimensōes inicialmente enunciadas.

A apresentação como um só dos três eixos analíticos que atravessam o conceito de fit body é para fins expositivos, pois não se deve entender que os mesmos operam independentemente. Ao contrário, eles estão num estado de permanente dinamismo e tensão, e no seu interior se revelam (des)articulações, tornando-se novas combinações de sentidos que pintam com diversas cores aquele quadro categórico.

Em consequência, desde o ponto de vista estético, observamos um dispositivo publicitário e propagandístico que opera através de 
imagens de corpos atléticos, os quais se sustentam nos conceitos de beleza natural, maleabilidade corporal e vida equilibrada. Tais qualidades se obtêm pela mediação de exercícios específicos e pela prática de um estilo de vida saudável (Sassatelli, 2001; Landa, 2008, 2009a). ${ }^{5}$

Por outro lado, os programas de treinamento e as aulas de fitness grupal que se realizam, por exemplo, nas academias baseiam-se numa concepção econômica e físico-anatômico-fisiológica do corpo (Crisorio, 1995). Os saberes que produzem e regulamentam os sistemas de exercícios que podem/devem se realizar na academia são a medicina, as ciências do treinamento e as teorias do management.$^{6}$ A retórica de transformação corporal, em consequência, está regida por um conjunto de princípios racionais que organizam o movimento em parâmetros padronizados de prazos, séries, intensidades e frequências. É na eficiência destas planificações e no compromisso do cliente com o processo que se enraíza a lógica de modelagem e manutenção do corpo do fitness.

Enquanto isso, as técnicas corporais que promovem o fitness operam através de estímulos que estressam os processos orgânicos (o interior), os quais moldam e incidem sobre a aparência (exterioridade) do agente praticante. Esta exterioridade (aparência) está também regulamentada por uma ordem, por um ideal, ou seja, o conjunto de apreciações e processos de avaliação que medem e ponderam a eficiência/efetividade das técnicas usadas. Para isso, utilizam um padrão estético-ético: a imagem de um corpo ativo, vital, firme e flexível. Tanto o agente que treina quanto o sujeito que prescreve situam suas práticas nessas dimensões. São estas as que dão legitimidade aos parâmetros, concebidos em termos de êxito ou fracasso, que regulamentam a intervenção do corpo e os alcances da sua transformação (Sassatelli, 2001; Landa, 2009a).

Em um segundo nível, estas práticas também apontam a capacidade intrínseca do corpo, dimensão que fixa e regulamenta os limites e as potencialidades dos processos de transformação do fit body. Desde este lugar, o corpo é concebido em termos de natureza. As técnicas de modificação do corpo que propóe o fitness apresentam especificidades frente a outras propostas de transformação corporal. Por exemplo, as intervenções cirúrgicas com fins estéticos, sob a ótica do fitness, são apreciadas como artificiais ou antinaturais (Sassatelli, 2001; Landa, 2008, 2009a). A esse respeito, são alusivas as palavras de um pioneiro deste campo, quando lhe questionei, para minha pesquisa, sobre qual é a relação do fitness com 
Os corpos da liderança: as tramas da ficção do dispositivo cultural do fitness

os conceitos de saúde, estética e qualidade de vida. Ele disse: "Aponta às três coisas e trata das pessoas, de dissuadi-las e seduzi-las para que essas pessoas não tenham que ir para uma cirurgia estética”. Então, imediatamente, perguntei-lhe: "E por que não tem que ir a uma cirurgia pelo estético", ao que ele respondeu: "Se algo se pode obter naturalmente, para que obtê-lo artificialmente?".

Segundo as palavras do entrevistado, a verdadeira transformação do corpo deve realizar-se por meio de processos naturais. Precisamente, um caráter distintivo do corpo do fitness $^{7}$ é a ética da sua produção/transformação. Ou seja, o sujeito que consome o fit body deve participar ativamente no processo de modificação e manutenção do (próprio) corpo. Ainda, sua disciplina e sua capacidade de esforço são os elementos-chave na aquisição do produto corporal desejado. Disso surge que o conceito de natureza no paradigma do fitness regulamenta as práticas de transformação do corpo em dois níveis: a) o nível da definição de uma estética (natural); e b) o nível dos processos de transformação legitimados (intervenção natural em um corpo concebido como organismo).

Nesse sentido, instrumentalidade, funcionalidade e beleza parecem que se complementam na cultura do fitness (Sassatelli, 2001; Landa, 2009a). Um corpo ágil, flexível e energético responde eficazmente às demandas laborais e sociais atuais. Representa um corpo útil. Produzir um corpo com tais características pode ser interpretado como uma atualização de uma estética da funcionalidade no interior destas práticas (que é extensiva ao espaço laboral e social). No mundo moral do fitness, o indicador por excelência que mede o nível de rendimento, autocontrole e adaptabilidade que o sujeito possui é o corpo. Nessa matriz ético-estética e sanitária, o fit body constitui-se num signo de valoração, medição e exclusão/inclusão dos sujeitos que se inscrevem nas lógicas do (auto)disciplinamento e da normalização estabelecidas pela cultura corporal do fitness (Landa, 2009a).

Este corpo se prescreve como empresa e, ao produzir-se, recria uma subjetividade flexível às exigências do meio (idem, ibid.). $\mathrm{O}$ sujeito toma a própria vida como uma empresa e disciplina-se para não sucumbir aos múltiplos embates de uma sociedade que adoece e está em permanente transformação. O fit body, nas constelações laborais descritas, emerge como aquele capital corporal que melhor se adapta e responde às investidas do capitalismo avançado (Landa, 2009a; Landa \& Marengo, 2009). 
Como afirma Wittke (2005, p. 157), “o empresário emblema do capitalista tem-se coberto dos imaginários da eficácia, do êxito social, modelo de realização pessoal, deteriorando aquela imagem do agente de exploração do homem pelo homem”.

\section{Conclusão: corpos produtivos e subjetividades empresariais}

O presente estudo tentou mapear a atualização do ethos hegemônico do capitalismo avançado desde a análise das narrativas que se configuram ao redor do corpo ideal do fitness. Também se desenharam as dinâmicas de produção e transformação do fit body em termos éticos, estéticos, econômicos, políticos e sociais.

No ethos da liderança nas constelações das organizações do fitness, o que se enuncia é a conformação de uma cultura que promove um estilo de vida empresarial que se apresenta como ideal. Este ideal é sustentado pelo paradigma de um corpo extraordinariamente produtivo (Pierbattisti, 2008; Landa, 2009a).

Em consequência, as práticas corporais do fitness que estão nas diagramáticas sociolaborais pós-fordistas outorgariam ao praticante um repertório de recursos da própria personalidade e do corpo, adequados para navegar nas agitadas águas do mercado capitalista contemporâneo (Landa \& Marengo, 2009). O sujeito fitness é aquele modelo não só da perfeição estética, mas também, e fundamentalmente, um parâmetro sanitário que prescreve a sua contraparte como patológica.

Os dois ideais, o empresário e o atlético, são constitutivos de figuras/estigmas que conspiram contra sua consecução: a obesidade e a velha cultura estatal - ou seja, os não aptos (idem, ibid.). Em outras palavras, são o desviado e o normal, como modelo, estereótipo e encarnação de todas as prescrições (Landa, 2009a).

Contudo, os desviados, finalmente, podem ser todos: os flácidos/ as, os/as com sobrepeso, os/as velhos/as, os/as feios/feias, os/as muito magros/as, os/as sedentários/as, os/as muito preguiçosos/as. Em suma, as multiplicidades de práticas que oferecem estas organizações ginásticas se orientam aos potencialmente perfectiveis, os integráveis, segundo marca o estereótipo de moda prescrito (Foucault, 1991; Landa, 2009b).

Então, como um capítulo por vir, devemos penetrar e ir além de uma reflexão sobre as dicotomias destas tecnologias e destes universos 
sígnicos-culturais. Precisamos ampliar o horizonte do pensamento, em relação a um estudo pormenorizado do universo do fitness, que rompa com a fórmula reflexiva dual, em direção a uma imaginação sociológica que infira sobre o que nos acontece entre essas cruzadas dos corpos saudáveis e produtivos (Simón, 2001).

\title{
Notas
}

1. Christian Salmon (2008) evidencia, no seu livro, a emergência de uma técnica de relatar, a estratégia do storytelling, que se tem expandido paulatinamente no mundo do management, a esfera da propaganda e o universo da comunicação política. O autor indica como um relato bem construído é capaz de ser interiorizado pela audiência, construir sentido e camuflar-se no mundo real.

2. Quer-se destacar que a palavra physicial fitness na língua inglesa remete a um estado relativo do corpo humano, um nível de competência de um sujeito $\mathrm{X}$ e sua capacidade de ter êxito em particulares condiçóes socioambientais; estado que se pode obter por meio de qualquer configuração de movimento ou intervenção sistemática sobre os corpos, assim como uma condição corporal ótima, na língua castelhana (Landa, 2009a).

3. A expressão relatos maestros, na língua castelhana e no (com)texto de este parágrafo, referese àquelas ficções narrativas, de caráter persuasivo, que delimitam as categorias e os projetos identitários/as possiveis e desejáveis, no marco de uma conjuntura sócio-histórica específica (neste caso, a sociedade contemporânea). O corpo, dada sua centralidade como vetor da construção subjetiva e identitária, se configura como um ponto estratégico de ditas máquinas narrativas (Butler, 1997; Nouzeilles, 2000).

4. Fitness, no contexto da minha pesquisa e neste artigo, representa esse conjunto de empresas de serviços que promovem uma cultura do corpo específica, por meio de: a) oferta de um conjunto de produtos desenhados para a transformação corporal dos sujeitos que a consomem e que, como efeito inovador, traz unida a incorporação de uma forma de vida; e b) capacitação e contratação de pessoas/profissionais que (re)produzam e deem permanência às dinâmicas culturais e de interação destas organizações (Landa, 2009a).

5. Algumas das revistas especializadas em fitness que circulam na Argentina são: Cuerpo \& Mente en Deportes, Men's Health, Women's Health, entre outras. As imagens que mencionamos aparecem nessas publicações. Esse material tem sido trabalhado com maior aprofundamento em Landa (2009a).

6. Nas ciências da administração, análise institucional ou da psicologia organizacional, a noção de management, em seus diversos modelos, refere-se à disciplina específica encarregada da produção teórico-prática de saberes e técnicas, orientados à gestão e à organização do processo produtivo nas instâncias empresariais contemporâneas.

7. Frente a outras técnicas de transformação corporal.

\section{Referências}

\author{
BAUMAN, Z. Postmodernity and its discontents. Nova Iorque: NY \\ University Press, 1997.
}


BUTLER, J. The psychic life power: theories of the subjection. Nova Iorque: Stanford University Press, 1997.

BOLSTANSKI, L.; CHIAPELLO, E. El nuevo espiritu del capitalismo. Madri: Akal, 2002.

CRISORIO, R. Enfoques para un abordaje de CBC desde la Educación Física. Serie Pedagógica, La Plata, v. 2, p. 175-192, 1995.

DU GAY, P. Organización de la identidad. Gobierno empresarial y gestión pública. In: HALL, S.; DU GAY, P. Cuestiones de la identidad cultural. Buenos Aires: Amorrtou, 2003. p. 251-280.

FOUCAULT, M. Tecnología del yo. Barcelona: Editorial Paidós, 1991.

FOUCAULT, M. El nacimiento de la biopolitica. Buenos Aires: Fondo de Cultura Económica, 2007.

FUSS, D. Dentro/fuera. In: CARBONELL, N.; TORRAS, M. Feminismos literarios. Madri: Lecturas, 1999. p. 113-124.

LANDA, M.I. El porvenir de los cuerpos rentables: un análisis de la práctica del fitness. In: CRISORIO, R.; GILES, M. Estudios críticos de la educación física. La Plata: Editoriales Al Margen, 2008.

LANDA, M.I. El porvenir de los cuerpos rentables: un análisis del dispositivo cultural del fitness en Argentina. 2009a. Dissertação (mestrado em Literatura Comparada: Estudos Literários e Culturais) - Universidad Autónoma de Barcelona, Barcelona.

LANDA, M.I. Subjetividades y consumos corporales. Un análisis de la práctica del fitness en España y Argentina. Razón y Palabra, México, DF, v. 14, n. 69, jul./set. 2009b. Disponível em: <http://www. razonypalabra.org.mx/SUBJETIVIDADES\%20Y\%20CONSUMOS \%20CORPORALES\%20UN\%20ANALISIS\%20DE\% 20LAS\% 20 PRACTICAS\%20DEL\%20FITNESS\%20EN\%20ESPANA\%20Y\% 20ARGENTINA\%20.pdf>. Acesso em: 20 set. 2009.

LANDA, M.I.; MARENGO, L. El cuerpo del trabajo en el capitalismo flexible: lógicas empresariales de gestión de energías y emociones. In: JORNADAS DE ESTUDIOS INTERDISCIPLINARIOS SOBRE CUERPO(S), SUBJETIVIDAD(ES) Y CONFLICTO(S) HACIA UNA 
Os corpos da liderança: as tramas da ficção do dispositivo cultural do fitness

SOCIOLOGÍA DE LOS CUERPOS Y LAS EMOCIONES DESDE LATINOAMÉRICA. Córdoba: UNC/CEA-Conicet, 2007.

LANDA, M.I.; MARENGO, L. Biopolíticas empresariales en la Argentina contemporánea: usos y articulaciones del fitness en contextos productivos emergentes. In: CONGRESO TRANSDISCIPLINAR SOBRE EL CUERPO. El cuerpo: objeto y sujeto de las ciencias humanas y sociales. Anais... Barcelona: Institución Milá; CSIC, 2009.

NOUZEILLES, G. Ficciones somáticas: naturalismo, nacionalismo y políticas médicas del cuerpo (Argentina 1880-1910). Rosario: Beatriz Viterbo, 2000.

PIERBATTISTI, D. La privatización de los cuerpos: la construcción de la proactividad neoliberal en el ámbito de las telecomunicaciones, 1991-2001. Buenos Aires: Prometeo Libros, 2008.

SALMON, C. Storytelling: la máquina de fabricar historias y formatear mentes. Barcelona: Ediciones Península, 2008.

SASSATELLI, R. The commercialization of discipline: keep-fit culture and its values. Journal of Modern Italian Studies, v. 5, n. 3, p. 396-411, jan. 2001. Disponível em: <http://www.ingentaconnect.com/content/ routledg/rmis/2001/00000005/00000003/art00016>. Acesso em: 2 jan. 2007.

SIMON, M.G. Cuerpos y subjetividades en las narrativas mediáticas: una aproximación sociosemiótica a los imaginarios del cuerpo en semanarios de la Argentina actual. 2001. Dissertação (mestrado em Sociossemiótica) - Centro de Estudios Avanzados, Universidad Nacional de Córdoba, Córdoba.

SMITH MAGUIRE, J. Fit for consumption: sociology and the business of fitness. Nova Iorque: Routledge, 2008.

TORRAS, M. El delito del cuerpo. In: TORRAS, M. Cuerpo e identidad I. Barcelona: Ediciones UAB, 2007.

VÁZQUEZ GARCÍA, F. Empresarios de nosotros mismos. Biopolítica, mercado y soberanía en la gubernamentalidad neoliberal. In: 
UGARTE PEREZ, J. La administración de la vida: estudios biopolíticos. Barcelona: Anthropos, 2005. p. 73-103.

WITTKE, T. La empresa: nuevos modos de subjetivación en la organización del trabajo. In: SCHVARSTEIN, L.; LEOPOLD, L. Trabajo y subjetividad: entre lo existente y lo necesario. Buenos Aires: Editorial Paidós, 2005.

Recebido em 5 de abril de 2011.

Aprovado em 30 de junho de 2012. 